\title{
LA VILLANA DE SAYAGO O SANCHO PUESTO A PRUEBA (II, 8-10, ANTECEDENTES Y CONSECUENTES)
}

\author{
Gregorio Torres Nebrera \\ Universidad de Extremadura
}

\begin{abstract}
What Cervantes tells in chapter X of the Segunda Parte, when Don Quijote has just leaved for the third time, will be really important for the development of the rest of the book. He has decided to pay homage to his beloved lady in her own village, El Toboso, and he entrusts Sancho with such a delicate job. Sancho has no other choice than lying to the knight again, the same as he did when he did not accomplished the task of carrying a letter from Sierra Morena. This lie will cause a series of connected facts that will put to test Sancho's ethics and capacity of decision.

halléla encantada y convertida de princesa en labradora, de hermosa en fea [...] de Dulcinea del Toboso en una villana de Sayago (Quijote II,32, 896)
\end{abstract}

Cervantes procuró ser consecuente, en la redacción de la segunda parte de su gran novela, con lo que sus personajes centrales, Caballero y Escudero, habían dicho y hecho en la entrega anterior. Y no sólo Cervantes, sino también los privilegiados lectores ficticios de aquella primera parte, como fueron los Duques, que oportunamente le dieron a Sancho la satisfacción que siempre anheló (salió al camino movido fundamentalmente por tal acicate) como fue la de ponerle al frente de una ínsula de tierra adentro. Y si Don Quijote toma la ruta de Zaragoza, hasta que las noticias de la apócrifa criatura de Avellaneda se lo desaconsejan, es porque ese proyectado viaje ya lo había anunciado el narrador en el capítulo I, 52, y confirmado en el cuarto capítulo de la segunda parte, cuando Carrasco recomienda a su vecino don Alonso que "fuese al reino de Aragón y a la ciudad de Zaragoza, adonde, de allí a pocos días, se habían de hacer unas solenísimas justas por la fiesta de San Jorge, en las cuales podría ganar fama sobre todos los caballeros aragoneses, que sería ganar fama sobre todos los del mundo"1 (II, 4, 659).

El encuentro de don Quijote con la aldeana en la que atisba la desgracia de Dulcinea, que es su propia desgracia, es un episodio que no se limita a su concreto momento, en la Segunda Parte de la novela en la que se produce, sino que se proyecta como un intenso y mantenido leit-motiv a casi todo lo largo del Quijote de 1615. El caballero intuye que tiene ante sí, nada más empezar esta nueva andadura, el posible signo de su derrota, o al menos, la empresa más difícil de cuantas ha de realizar, porque es en la que más le va su fama y su imagen ante sí mismo: que los encantadores le hayan hurtado la contemplación del norte de todos sus sueños; y, por tanto, en todo lo que le quede de vida caballeresca rumiará la ausencia de Dulcinea, encerrada en su encantamiento, y todos sus esfuerzos estarán

\footnotetext{
${ }^{1}$ Las citas de la novelas las hago por la edición del "Instituto Cervantes" dirigida por Francisco Rico. Barcelona, Crítica, 1998. En cada caso indico parte, capítulo y página.
} 
dirigidos a remediar la grave ofensa que se le está haciendo a la primera de las damas que sobre el universo de la caballería habían sido.

El episodio en el que me voy a centrar es la primera consecuencia, ya en el Quijote de 1615, de una peligrosa e incómoda mentira de Sancho en la entrega anterior de 1605 . No quiso reconocer entonces el abnegado escudero dos de sus limitaciones: el olvido en llevarse consigo el "librillo" de Cardenio en donde iba registrada la misiva a la señora, escrita de puño y letra de don Quijote, y su pésima memoria (sobre su analfabetismo) para recordar los términos de la carta, pese al esfuerzo de don Quijote en repetírselos (I, 25, ) Y sobre ellos, el desistir de ir, en verdad, a visitar a la ya mencionada Aldonza Lorenzo, probable vecina del Toboso, en un acto de desprecio, más que por su señor, por la moza a la que supone va a encontrar, y sobre la que su amo ha dado en edificar la entelequia de Dulcinea. Pues el caballero ha tenido una debilidad en sus confidencias con Sancho: reconocer que la persona real sobre la que (tal vez) ha ideado su fantasía es una vecina del cercano pueblo de El Toboso, y de concreta filiación (porque fue muchacha de la que en algún momento el hidalgo se sintió enamoriscado y porque, al fin, don Quijote no puede prescindir de un requisito fundamental en el código caballeresco - la amada- y la elabora sobre el entorno próximo que le rodea, como ha procedido en los demás elementos que le han ido conformando como manchego caballero andante). Pero al mentar ese lejano modelo de Aldonza Lorenzo en la confidencia a Sancho, don Quijote pone en manos de su escudero un arma peligrosa que aquél utilizará contra éste, contra su buena fe: ya tiene Dulcinea cuerpo, manos, pies y, sobre todo, ya tiene Dulcinea, para Sancho, una cara, un aspecto que recuerda con admirativa ponderación: "Bien la conozco [...] moza de chapa, hecha y derecha y de pelo en pecho, y que puede sacar la barba del lodo a cualquier caballero andante, o por andar, que la tuviere por señora!" (I, 25, 283). Es decir, moza de excelentes cualidades, valiente y que puede sacar a cualquiera del aprieto o compromiso en que esté metido. Cualidades que, sumadas a otra que Sancho dice en primer lugar, la de su fuerza física ("tira tan bien una barra como el más forzudo zagal de todo el pueblo") nos llevan a pensar más en el retrato de la serrana que empezara a acuñar Hita y a desarrollar Lope o Vélez en el teatro que en una delicada y elegante dama, como serían todas las derivadas de la tipología de Oriana.

Sancho tuvo ocasión de reconocer tales errores ante su señor, que de seguro lo hubiese comprendido sin demasiado esfuerzo, superado el primer momento de cierto enfado, que sería menor, pues lo sería sobre un acto de cierta negligencia, pero nunca sobre un deliberado engaño. Pero, celoso de su tranquilidad y temeroso de perder el favor prometido por el caballero, Sancho opta por mentir, sin sospechar que la dichosa mentira se volvería contra él, lo iría poniendo a prueba en las etapas siguientes. Es más: para darle más credibilidad a su mentira, y probablemente para que quedase más satisfecho su señor y no insistiese en su enojoso interrogatorio, Sancho le transmite a don Quijote un ficticio encargo de la fícticia Dulcinea, que es la génesis de este episodio de la Segunda Parte: que la dama emplaza al enamorado caballero a una cita personal en su villa de El Toboso: "Y, finalmente, me dijo que dijese a vuestra merced que le besaba las manos, y que allí quedaba con más deseo de verle que de escribirle; y que, así, le suplicaba y mandaba que, vista la presente, saliese de aquellos matorrales y se dejase de hacer disparates, y se pusiese luego luego en camino del Toboso, si otra cosa de más importancia no le sucediese, porque tenía gran deseo de ver a vuestra merced' ( I, 31,360; el subrayado es mío). Al reanudar la vida 
caballeresca, después de la última tarea -atender los ruegos de Micomicona, aunque realmente hubiese parado no en el exótico reino africano sino en el bien cercano "lugar de la Mancha" del que había salido- don Quijote se apresura a satisfacer la petición de la Dulcinea que llena el centro de sus ocupaciones y preocupaciones. Por ello, helos aquí, en el capítulo IX, a Don Quijote y a Sancho camino del Toboso.

Por ello el escudero se encuentra atrapado en su propia red, en la mentira urdida para salir del paso en ocasión anterior. Con su invención le dio alas y consistencia a la imaginación quijotesca sobre la etérea Dulcinea: si su buen escudero y confidente la ha llegado a ver y hablar, aunque ya velada, mediatizada por los encantadores, eso le sirve para concederle un tanto de existencia. Y ese atrevimiento se ha de pagar.

Don Quijote, en su tercera salida, no deja al albur del caballo la dirección a tomar. Tiene un destino perfectamente preconcebido (un destino que será luego su destino caballeresco por antonomasia): visitar, antes que nada, a su doña Dulcinea en el palacio de El Toboso. Así lo tiene dispuesto ya en el mencionado capítulo cuarto de esta segunda parte, cuando le encarga a la habilidad compositiva de Carrasco "unos versos que tratasen de la despedida que pensaba hacer de su señora Dulcinea del Toboso" (II, 4, 661) a modo de acróstico. Si en la primera de las salidas don Quijote cumple con un requisito sine qua non puede dar un paso adelante, como es el de ser armado caballero, ahora ha de cumplir con la otra exigencia que más lo acaba de perfilar en tanto caballero: rendir pleitesía a su dama, pues al fin "caballero sin dama era como un cielo sin estrellas o un árbol sin hojas" (I, 1, 43). Es la segunda exigencia, que don Quijote ahora quiere llevar a efecto. Y si la primera, la ordenación de caballero, quedaba desautorizada objetivamente en el "contrarritual" burlesco de la venta, lo mismo va a ocurrir con esta segunda: va a ponerse a los pies de una hosca, fea y desagradable aldeana. Pero con una considerable diferencia entre ambos momentos: las aristas burlescas, inauténticas, de aquella liturgia de la caballería no fueron advertidas por el caballero, pues en el tiempo de las dos primeras salidas don Quijote antepone la realidad inventada al fondo desvaído, neutralizado de la realidad real; ahora sí parará mientes en el desajuste ¡tan doloroso! que se levanta ante él. Don Quijote avanza, como avanza la novela, en su posicionamiento ante la realidad. Ahora casi siempre tiene una postura más objetiva, incluso más nítida, ante lo que se yergue a sus ojos (frecuentemente, por ejemplo, no confunde ventas con castillos). Cree lo que realmente ve; otra cosa bien distinta es que tenga a su lado mediatizadores de esa realidad. Así son los Duques, así lo había sido poco antes el sagaz pastor Basilio, así lo será don Antonio Moreno, así lo es, enmarcando en el principio y el final Quijote II, Sansón Carrasco; así, en definitiva, actúa también, para salir del apuro, para superar la prueba, el escudero que se alinea con los otros engañadores del bienpensante Don Quijote.

Por ello hay que advertir que en este episodio empieza la hora de Sancho. Hasta aquí el cazurro personaje se ha mostrado casi enteramente pasivo, salvo la ocurrencia, probablemente poco meditada, de mentir a su señor; digo poco meditada, porque entonces no calculó el compromiso en que se podía ver envuelto. Ahora se le pone en un brete que ha de resolver con una muestra de ingenio personal. Sancho empieza a ser un personaje activo, con su propia iniciativa: un paso adelante en su conformación de carácter que se confirmará con la experiencia, resolutoria, en el gobierno de la Ínsula, y con los ánimos, generosos, compensadores de aquella primera mentira, del final de la novela, cuando quiere salvar en 
última instancia al agonizante don Alonso invitándole a la utopía pastoril, ya que ha quedado anclada, y mojada, en una playa de Barcelona, la utopía caballeresca.

Pero ¿con qué intención, realmente, podemos presumir que va don Quijote al Toboso? ¿Para ver a una Dulcinea concreta y real o por otra motivación?

No parece que por lo primero, o por lo menos no lo parece del todo ¿Acaso ha olvidado que le había reconocido a Sancho, allá en Sierra Morena, que su Dulcinea es antes fruto de su imaginación que realidad, solo idealizado perfil en el que acomodar el paradigma imaginario de la dama que se le exige al caballero, puesto sobre el leve soporte de una mal recordada Aldonza Lorenzo, aquella labradora, por la descripción de Sancho, no muy distinta, incluso peor, que la que el escudero encuentra en el camino y le saca del atolladero? Don Quijote se extraña, a la fuerza, de que la mujer que le dicen ser su imaginada dama - sin haberla visto antes- no se corresponda con los conceptos de esa imaginación, que esté muy lejos del paradigma que se había formulado para sus adentros. Así se lo reconoce a los Duques cuando le sacan el tema en la tertulia de sobremesa (II, 32): no declara abiertamente que sea una invención suya, podría existir o no, pero en cualquier caso él la imagina y la espera como le ha acostumbrado la imaginación caballeresca a que lo sea: " Dios sabe si hay Dulcinea o no en el mundo, o si es fantástica o no es fantástica [...] Ni yo engendré ni parí a mi señora, puesto que la contemplo como conviene que sea una dama que contenga en sí las partes que pueden hacerla famosa en todas las del mundo" (II,32, 897). Para nada don Quijote especifica unos rasgos concretos de mujer. Es lo que fue siempre, una idea antes que una entidad corporal.

Entonces, repitámonos la pregunta: ¿a qué decide ir don Quijote al Toboso? ¿Tal vez a obligar a Sancho a que reconozca que ha caído en un grave pecado, impropio de la orden caballeresca, como es el mentir? : "que nos mandan que no digamos mentira alguna, pena de relasos" (I, 25, en la medida en que don Quijote hace partícipe de esta obligación al escudero del caballero).

Y lo peor es que Sancho se mantiene en sus trece de la mentira. Cuando don Quijote, en II,8, comenta su deseo de visitar a Dulcinea para recibir su bendición, Sancho se cura en salud recordándole circunstancias del mentido encuentro que ya habían sustentado su mentira anterior, y provocando el mismo desacuerdo en su señor, que admite las bardas de la casa aldeana en vez de las almenas del palacio o castillo, pero vuelve a resistirse en la acción de la Dulcinea que se había inventado su escudero: en ningún caso puede admitir que la Dulcinea de la que ambos están hablando se dedicase a cernir trigo rubión. Lo que para Sancho se acomodaba a su experiencia contravenía todo el paradigma tipológico de don Quijote, pues "es un menester y ejercicio que va desviado de todo lo que hacen y deben hacer las personas principales" (II, 8, 688). Don Quijote se empeña en que Sancho haga verdad la mentira que urdió. Cuando, en el capítulo noveno, Sancho está a punto de reconocer su engaño, confesando (animado por la coherencia de D. Quijote) que él, como su señor, jamás había visto a la señora Dulcinea, el Caballero de la Triste Figura le aprieta el nudo corredizo de su engaño ("Eso no puede ser, que por lo menos ya me has dicho tú que la viste ahechando trigo, cuando me trujiste la respuesta de la carta que le envié contigo" II, 9, 697). En el fragor de la discusión Sancho se siente presionado, cercado, y sale por donde puede. Si su amo ha dicho que jamás vio a Dulcinea, y que solo la ama "de oídas", Sancho coge la ocasión por los pelos y se aplica la misma coartada, en él más indigna porque reconoce la vil mentira: "también fue de oídas la vista y la respuesta que le 
truje" (II, 9, 697). Ahí quería Don Quijote llegar: a que Sancho confesara su desleal burla con algo tan fundamental en su código caballeresco como es la sinceridad. Y se oye por fin la sentencia del reproche, de la corrección moral en la que Sancho debe pulirse: "tiempos hay de burlar, y tiempos donde caen y parecen mal las burlas" (II, 9, 697).

Don Quijote se está preparando para lo que, tal vez, ya sabe que ha de ser una incómoda frustración: no hallar la mansión de Dulcinea (¿también vale como anuncio premonitorio para la frustración mayor del encuentro con la fea aldeana del capítulo siguiente?). Primero ha encontrado presagios negativos en los ladridos de perros, rebuznos de asnos, gruñidos de puercos, maullidos de gatos; luego en el motivo romanceril del madrugador labriego con el que se topan (la derrota de Roncesvalles, en el comienzo de un romance carolingio muy difundido, dedicado al cautiverio del conde Guarinos). Además, recuérdese que en el capítulo XXXI del texto de 1605 Sancho ya había salido al paso de la situación en la que ahora se ve seriamente comprometido, aconsejándole a su señor que "no se cure de ir por agora a ver mi señora Dulcinea, sino váyase a matar al gigante, y concluyamos el negocio" (I, 31, 363), pues el interesado escudero sabe de la inexistencia de la dama manchega al tiempo que encuentra mucho más rentable acudir a la ayuda de la misteriosa dama africana bautizada como Micomicona.

La acción ocurre en plena noche, y, además, en una "noche entreclara", o sea, anubarrada, con disminución de luminosidad: ello dificultaría, de suyo, dar con la mansión de Dulcinea (si ambas existiesen; por ello los dos jinetes se equivocan, y topan con la fábrica de la iglesia cuando creía don Quijote que podían ser los muros de la mansión de su señora ${ }^{2}$ ); pero también esas sombras ayudan a mantener el engaño, pese a que Sancho se ha mostrado por un instante dispuesto a reconocerlo, cosa que Don Quijote no le ha admitido porque quiere tensar más la cuerda de la prueba o porque no quiere agotar tan pronto la ilusión que le hace saberse tan cerca de la dama a la que ha dado alas de consistencia la invención de su escudero. Por ello cuando empieza a amanecer, cuando las luces pueden reducir la cobertura del engaño, Sancho, que ha vuelto a dejarse llevar por la mentira que le acredita ante su señor, convence a Don Quijote para que aguarde lejos su gestión de búsqueda de Dulcinea, es decir su segunda embajada a El Toboso. Logra así volver a una situación parecida a la que se le planteaba en los días de Sierra Morena: Don Quijote aguardará escondido en un bosquecillo de las afueras el regreso de Sancho, como entonces, con las manos llenas o con las manos vacías. Y Sancho repite situación, solo que ahora no tiene la embajada de trasladar una carta, como solución a mano, y soporte de su estrategia, sino el mucho más difícil encargo de convencer a la misma Dulcinea para que acepte la visita del Caballero. Pero ¿a quién ha de convencer? Sancho ha sido emplazado a la captación de un imposible, y él lo sabe. Entonces la distancia que mediaba entre su señor y la dama anhelada iba en su favor; ahora obra en su contra.

Probablemente Don Quijote espera un desenlace parejo al de meses atrás: regresará Sancho con una parecida o distinta imagen de la Dulcinea que entonces dijo conocer, y todo seguirá en la misma ambigüedad: Sancho dirá de la imagen que él ha visto, y don Quijote

\footnotetext{
${ }^{2}$ Es el momento de que Don Quijote señale aquello de "Con la iglesia hemos dado, Sancho" (II, 9, 696) Y desde luego don Quijote encontrará los más agresivos censores de sus creencias caballerescas en tres curas: el que le hace el "escrutinio" de su biblioteca particular, el que destaca los defectos de las novelas de caballerías y el que, en la comida con los duques, abandona la mesa avergonzado de compartirla con un sandio y con un loco.
} 
continuará traduciéndola a la que le conviene. Pero Cervantes pone a prueba a Sancho, le da la primera oportunidad de su autonomía, de su natural capacidad de resolver problemas (como luego lo mostrará con envidiable sentido común y perspicacia en la ínsula). Al escudero se le ha acabado el recurso de seguir pintando una caricatura de la dama sobre el vago recuerdo que tiene de Aldonza Lorenzo, que es lo que hizo en la ocasión de Sierra Morena. Tiene que idear una nueva estratagema para salir airoso de la trampa que le ha urdido su señor, para "traerle tan buena respuesta como le trujo la vez primera" (II, 10, 700) pero sin olvidar que ahora don Quijote espera la taxativa cita con la dama, lo que supone bastante más que en la otra ocasión. Si en Sierra Morena solo aspiraba a conocer la reacción y manifestación de la mujer ante la carta recibida y leída (la lejanía entre el pueblo y el lugar de la penitencia le daba mucha más capacidad de maniobra a Sancho), ahora la cercanía facilita un grado más de expectativa: recibir la venia para visitarla, para verla. El riesgo, por tanto, es mucho mayor; la astucia del labriego tiene que ser más rápida y aguda. Sancho se da cuenta de que el engaño primero le ha llevado a "una callejuela sin salida" (el lugar en donde dice que debe hallarse el palacio de Dulcinea). El escudero se afana en ganar tiempo y hallar el modo de solucionar el compromiso. A Sancho le cabe la duda, en la insistencia de Don Quijote, de que la dichosa Dulcinea haya sido conocida e incluso visitada alguna vez por su señor, pero vuelve a comprobar que tiene libre el camino de la invención, porque Don Quijote se ratifica -leal a sí mismo- en afirmaciones anteriores: "¿no te he dicho mil veces que en todos los días de mi vida no he visto a la sin par Dulcinea, ni jamás atravesé los umbrales de su palacio, y que solo estoy enamorado de oídas y de la gran fama que tiene de hermosa y discreta?" (II, 9, 697).

Ante la respuesta de don Quijote, Sancho tiene la tentación de escaparse por el portillo más próximo: él tampoco la ha visto, dice, y por tanto huelga buscar (y encontrar) a alguien a quien ninguno de los dos conoce; pero olvida que el caballero no ha echado en saco roto su engaño anterior, que le persigue y le devuelve al encierro de su compromiso. "Eso no puede ser; que por lo menos ya me has dicho tú que la viste ahechando trigo cuando me trujiste la respuesta de la carta" (II, 9, 697). ¿Qué hacer entonces? Sancho está nervioso como niño cogido en falta, y la inmediata respuesta se apoya en una expresión que había encontrado en el propio idiolecto de Quijote: Dulcinea es una criatura concebida y alimentada en el "amor de oídas" o "amor de lejos" de la filografía trovadoresca. Y Sancho prueba a ver si cuela su excusa: "también fue de oídas la vista y la respuesta que le truje" (II, 9, 697). Pero don Quijote no puede admitir tal causa de que ahora no sepa hallar el lugar de la cita en medio de la noche tobosina, porque admitirlo sería aceptar que Sancho se burló de su buena fe y de toda su meritoria penitencia en los cerros serranos. Sancho es quien ahora pone a prueba la mansedumbre y la paciencia del enamorado. Don Quijote tiene una nueva oportunidad de darse cuenta de la superchería -entonces- de su escudero; incluso parece que lo sospecha, cuando vuelve a recordarle que, a diferencia de él, Sancho sí visitó y vio a Dulcinea, al margen de que estuviese o no enfrascada en tareas impropias de su alcurnia: "No porque yo diga que ni he visto ni hablado a la señora de mi alma has tú de decir también que ni la has hablado ni visto, siendo tan al revés como sabes" (II, 9, 697698). Estamos donde estábamos. Sancho no parece tener escapatoria y el reto de dar con el palacio de Dulcinea sigue estando en pie. ¿Qué hacer? De momento le salvará la campana, o mejor dicho, el encuentro con un labrador que sale al campo con sus aperos de labranza y va cantando un romance. 
Vuelve a hacerse presente el motivo del Romancero en el Quijote. Y de nuevo la cita pertenece al frecuentado ámbito del "romancero carolingio". Ahora es el inicio del "Romance del Conde Guarinos" el que escucha la noctívaga pareja, aludiendo a la derrota de Roncesvalles, con una variante de la que Cervantes no se percató y que curiosamente luego repone, en su comentario, el mismo Sancho ${ }^{3}$. Don Quijote, como en otras ocasiones (al comienzo de esta misma tanda de capítulos, sin ir más lejos ${ }^{4}$ ) considera el encuentro como un signo premonitorio: si el romance recordaba la derrota del ejército de Carlomagno en el paso fronterizo, la excursión del Caballero y del Escudero por las callejas de El Toboso será también, muy probablemente, inútil. Notemos cómo para don Quijote la Literatura tiene una decisiva capacidad de conformar la realidad. Es ahora, con la sugerencia de la derrota caballeresca evocada por el texto romanceril, cuando Don Quijote aplaza la búsqueda de la amada, pues admite que el primer intento de hallazgo sería fallido, acabaría en derrota.

Puestas así las cosas, y cuando la llegada de un nuevo día le privará a Sancho de la excusa de la noche sin luna para encontrar la mansión de Dulcinea, don Quijote cederá a retirarse del lugar de operaciones. Sancho, habilidoso, le pone a tiro una excusa que el caballero acepta de inmediato porque -y es otro indicio de que don Quijote está evolucionando- empieza a tener sentido del ridículo, y entiende que ser visto por los vecinos de un pueblo cercano al suyo buscando a una mujer que (lo puede sospechar el hidalgo) no existe más que en su deseo, podría ir en "menoscabo de su honra y fama" (II, 9, 699). ¿Dónde se ha visto - podría pensar también don Quijote- un caballero andante que esté buscando, desorientado, a la dama de sus pensamientos en medio de las callejuelas de una humilde aldea? Pero tal vez haya parado mientes en lo que antes le ha dicho Sancho y no quiera seguir más allá, no quiera darse de bruces con el hecho de que está siguiendo un rastro vano, porque ha sido víctima de las mentiras de un lugareño. Don Quijote decide huir de la enojosa situación, ponerse a cubierto ("vamos a buscar donde me embosque"; II, 9, 699) y dejarle el terreno expedito a su ayudante para que Sancho pueda volver a mentirle, si quiere, pero todo antes que reconocer que Dulcinea no era más que una entelequia personal contrastada por la irresponsable invención de un humilde y grotesco aldeano cogido en falta.

Y Sancho, en la retirada todavía honrosa, halla un respiro, un plazo que le permita darle cuerpo (de Dulcinea) a la estratagema que prolongue una trascendental mentira. Don Quijote quiere encerrarse en el fondo de una floresta, o sea, ensimismarse, para seguir recreando el mito que podría hacerse añicos si permanece en poblado, y a la luz del día. En esta acción de esconderse en medio de un bosquecillo encuentro un adelanto del deseado descenso al interior de la cueva de Montesinos que sucederá unos capítulos más adelante. Son dos maneras parejas del ahondamiento del caballero en su propia intimidad, dos momentos de particular ascetismo que amplifican la primera retirada a Sierra Morena para hacer penitencia. Y de hecho, lo que le ocurre a don Quijote en esta floresta tendrá su

\footnotetext{
${ }^{3}$ En su lectura más difundida el aludido romance dice: "Mala la vistes franceses/ la caza de Roncesvalles", si bien el texto cervantino lee "Mala la hubistes, franceses/en esa de Roncesvalles". Y luego Sancho apostilla (de forma aparentemente inconexa): “¿qué hace a nuestro propósito la caza de Roncesvalles?”.

${ }^{4}$ Cuando se va a iniciar la tercera salida, el simultáneo relincho de Rocinante y el ventoseo del rucio "de entrambos, caballero y escudero, fue tenido a buena señal y por felicísimo agüero" (II, 8, 686)
} 
directa repercusión en la experiencia onírica que le sucederá en el fondo de la espelunca manchega.

El meollo de lo que me interesa comentar en esta ocasión se centra en el capítulo décimo de la segunda parte de El Quijote.

Cervantes acentúa la expectativa del lector, que ya debía de ser considerable pues se ha dado cuenta del conflicto en el que se ha metido Sancho por "mantenella y no enmendalla" [su mentira acerca de Dulcinea] con uno de esos comentarios referidos al narrador interpuesto, Cide Hamete, con los que suele abrir o interrumpir más de un pasaje (sobre todo en esta segunda entrega de su historia). Y de forma exagerada, pero conducente a incentivar dicha atención del lector, aduce el temor de inverosimilitud que confesaba "el autor desta grande historia", anunciando lo que no es verdad en términos absolutos ("las locuras de don Quijote llegaron aquí al término y raya de las mayores que pueden imaginarse", II, 10, 700) pero sí en términos relativos, pues lo que don Quijote ha de asumir en esta ocasión le determinará hasta el final de su vida y de sus andanzas. Con este párrafo prologal el lector acompaña la nueva "embajada sanchina" con la máxima atención y ya preparado para ver la bufa escena que está a punto de producirse, abusando de la buena fe del caballero. Una expectativa que aumenta un grado, pues esa embajada del escudero cerca de la dama no solo persigue unas palabras de aliento, como en la ocasión de la primera parte, sino su misma comparecencia junto al caballero. Don Quijote tensa la prueba a la que está sometiendo a Sancho, y quiere que su escudero se las arregle para corporizar a la que solo es una entelequia mental de su código caballeresco. No es pequeño el órdago, pero en el fondo don Quijote no confía demasiado en que la empresa se corone tal como él la ha formulado. Estaría dispuesto a recrear la imagen de su dama por los signos quinésicos y proxémicos de la mujer ante la embajada de Sancho. Se conformaría con ello, repitiendo lo recomendado en la ocasión de Sierra Morena. Como entonces, don Quijote encomienda a la atención y a la memoria de su buen Sancho el retrato animado de la fémina y de su reacción cuando oye hablar de su caballero reflejado por el escudero. En los dos momentos don Quijote tiene creada ya una foto fija del comportamiento de su amada. Una vez al interesarse por los efectos que le ha producido escuchar la carta que, de memoria, le ha trasladado Sancho; otra, adelantándose a los síntomas que expresarán el interés y amor de Dulcinea al recibir al emisario de don Quijote. Comparemos:

Quijote I, 31, 358: "Cuando le diste la carta, ¿bésola? ¿Púsosela sobre la cabeza? ¿Hizo alguna ceremonia digna de tal carta, o qué hizo? [...] ¿Qué te preguntó de mí? [...] ¿Qué hizo cuándo leyó la carta? [...] ¿Qué joya fue la que te dio, al despedirte, por las nuevas que de mí le llevaste?"

Quijote II, 10, 700-701: "Ten memoria y no se te pase della cómo te recibe: si muda las colores el tiempo que la estuvieres dando mi embajada; si se desasosiega y turba oyendo mi nombre; si no cabe en la almohada, si acaso la hallas sentada en el estrado rico de su autoridad; y si está en pie, mírala se pone ahora sobre el uno, ahora sobre el otro pie; si te repite la respuesta que te diere dos o tres veces; si la muda de blanda en áspera, de aceda en amorosa; si levanta la mano al cabello para componerle, aunque no esté desordenado".

Las previsiones de don Quijote en la primera embajada no se habían visto satisfechas porque Sancho había tirado por tierra, con su retrato infrarrealista, lo que el caballero consideraba, a la luz de la experiencia lectora acumulada, que debería ser. Ahora vuelve a la carga, y aventura un síndrome de amor en la mujer que, al contrastarlo con el cierto e 
inminente comportamiento de la villana de Sayago, volverá a producir un contraste burlesco que vuelve a dejar al hidalgo fuera de juego, y dolorosamente decepcionado.

Por otra parte el azar le pone en bandeja a Sancho la solución a su dilema, dentro de una inobjetable coherencia interna. Pero Cervantes retrasa un tiempo esa solución, tensa todavía la atención y expectativa del lector, y no nos hurta la preocupación y consternación del mentiroso escudero, cogido ahora en la propia trampa que él, inadvertidamente, se fue labrando.

Y nos situamos ante un espléndido soliloquio a dos tiempos de Sancho: en el primero - expositivo de la delicada y al unísono ridícula situación- se produce una suerte de desdoblamiento en el que Sancho dialoga con el otro "yo lógico" que anida en él, para distanciarse mínimamente y valorar lo ambiguo e inconsistente de su situación; y el segundo, para tomar una postura que le permita salir del atolladero, que no es sino volver a las andadas, y hacer de la primera mentira un engaño aún más grande. En estas reflexiones Cervantes cuida los detalles que corresponden al perfil nítido, idiosincrásico de Sancho. Así el personaje quiere descargar un tanto de su preocupación comparándola con lo que más le puede disgustar (haber extraviado a su rucio) y le concede un tanto de cinismo en el que parapetarse y justificarse: si su amo da muestras de indudable locura, tiene entonces campo abierto para enjaretarle un nuevo engaño, se cree con licencia de burla. Echa sobre la extravagancia de su señor parte de la responsabilidad en engañarle otra vez para procurar su escarmiento (Sancho se adelanta, inconscientemente, a las "cínicas" medidas terapéuticas que urde Sansón Carrasco y que, de ese modo, don Quijote desista de encargarle nuevas embajadas de tan comprometida y difícil resolución: "Quizá con esta porfía acabaré con él que no me envíe otra vez a semejantes mensajerías, viendo cuán mal recado le traigo dellas" II, 10, 703).

Pero volvamos a los razonamientos de Sancho con más atención. El personaje urde un autointerrogatorio que "objetiva" la situación que Cervantes ha llevado al límite del absurdo: ir a buscar a una absoluta desconocida a un lugar sobradamente conocido, subrayando la paradoja que se da entre ambos extremos; hallar una princesa que se pretende paradigma entre las princesas en un rústico poblachón manchego (con toda ironía Sancho dice "la gran ciudad del Toboso") y enviado por alguien que, creyéndose la flor y nata de la caballería, invierte la recta dirección de la realidad: "y da de comer al que ha sed, y de beber al que ha hambre" (II, 10, 702). Ante tal desatino el personaje imagina las consecuencias que puede traerle su extravagante búsqueda, y reaparece el Sancho que teme por su daño físico antes que procura por su amo. Es como si Cervantes quisiera castigar el inicial egoísmo del personaje haciendo que la suerte de Dulcinea, de la Dulcinea que él acabó inventando en sus circunstancias de dama encantada, dependa de su propio sufrimiento físico a golpes. Sancho sigue distanciándose de su señor, negando cualquier corresponsabilidad, que remite siempre al caballero en exclusiva: allá él. Sancho teme meterse en algún lío si le da gusto a don Quijote y se pone a la insólita tarea de buscar dama extraña entre sus paisanos. ¿Qué hacer entonces? Pues usar de las reservas. ¿No había descrito Sancho, semanas atrás, a Dulcinea en términos de aldeana trasegando trigo, tal vez porque pensaba en la Aldonza conocida? Pues ahondar por ese camino es una fácil tentación. Que don Quijote se encuentre con su anhelada Dulcinea en forma de rústica aldeana no sería sino confirmar que así la vio Sancho cuando dijo haberla visitado en la ocasión anterior, revalidando, de paso, la otra mentira con indicios de verdad. Al fin desde 
la experiencia acumulada que tiene de cómo su señor Don Quijote altera la realidad que salta a los ojos de los comunes mortales", "no será muy difícil hacerle creer que una labradora, la primera que me topare por aquí, es la señora Dulcinea" (II, 10, 703). Cervantes está concediendo a Sancho la primera ocasión de decidir por sí mismo y dictaminar sobre la realidad con la ayuda de la experiencia y conocimiento acumulados. Es el punto de partida de una evolución del personaje que llegará a su culminación de "autodeterminación" en los diversos episodios del gobierno insular. Cualquier aldeana, decide Sancho, podrá servir de Dulcinea, pues a fin de cuentas don Quijote había confesado no haber visto jamás a la dama de sus pensamientos; y si al caballero le cabe alguna duda (Sancho se adelanta, con razón, a las reticencias de su amo, decepcionado por la "Dulcinea" que le lleva su embajador) nada más fácil que acudir a la coartada-comodín que don Quijote viene usando desde el primer momento para acomodar la utopía caballeresca continuamente quebrantada a la realidad en torno: las interferencias de los malos encantadores "por hacerle mal y daño".

La estrategia decidida le parece tan bien traída en razón al escudero deliberante que "quedó sosegado su espíritu y tuvo por bien acabado su negocio" (II, 10, 704). Y aún hila más fino que en la embajada anterior, para evitar una posible sospecha de engaño por parte de su amo: entonces don Quijote se había admirado de la rapidez de Sancho en ir y volver al Toboso desde Sierra Morena en solo tres días ${ }^{6}$; ahora Sancho anda más cauto y aguarda, a escasos metros de su amo, el tiempo razonable y verosímil de ir y volver al pueblo cercano.

Tres aldeanas en sendos pollinos se introducen en el centro de la secuencia de ese capítulo X. Sancho ya tiene los personajes de su invención. Lo que luego harán sistemáticamente los Duques del camino aragonés (fabricar a los ojos crédulos y confiados de don Quijote una realidad engañosa que responda de todas todas al imaginario caballeresco) lo adelanta el escudero en la floresta manchega.

Sancho juega fuerte en su apuesta. Hace suyo el sistemático modo de filtrar a priori la realidad mostrenca en embellecida y falseada, pero dentro de las expectativas del ámbito caballeresco. Imita a don Quijote: si el caballero cerraba los ojos a los molinos que se levantaban en el cercano horizonte y se empeñaba en ver gigantes, y damas secuestradas en donde había burguesas y tranquilas viajeras, y complejos ejércitos acometiéndose sobre mansos rebaños que se cruzan en la cañada, Sancho finge ver lo que le hubiese gustado contemplar a don Quijote (lo que correspondería al retrato imaginario y previsto de Dulcinea) y no lo que realmente ve, y con él el lector, que es también lo que ve don Quijote. Porque en esta tercera salida el hidalgo ha cambiado en su postura ante la realidad: no la anula -para transformarla- como antes, sino que la admite en su marco más común y

\footnotetext{
${ }^{5}$ A través de la reflexiva y selectiva memoria de Sancho, Cervantes recuerda al lector de la primera parte una rápida síntesis de algunos de los atrabiliarios episodios de su amo en la anterior salida: "Siendo, pues, loco, como lo es, y de locura que las más veces toma unas cosas por otras, y juzga lo blanco por negro y lo negro por blanco, como se pareció cuando dijo que los molinos de viento eran gigantes, y las mulas de los religiosos dromedarios, y las manadas de carneros ejércitos de enemigos, y otras muchas cosas a este tono" (II, 10, 703).

${ }^{6}$ Entonces Don Quijote hizo unas observaciones "mágicas" que pudieron inspirar a los Duques la invención de Clavileño para atender la petición de doña Trifaldi: “Sabes de que estoy maravillado, Sancho? De que me parece que fuiste y veniste por los aires, pues poco más de tres días has tardado en ir y venir desde aquí al Toboso" (I, 31, $360)$.
} 
primigenio (otra cosa bien distinta es que otros, como ahora Sancho, como luego los Duques, le enseñen una realidad previamente manipulada por la palabra o por la "escenografía" que acompaña a esa palabra y la refuerza en su capacidad engañosa). En esta situación Cervantes invierte los papeles de las situaciones anteriores, pues Sancho declara ver lo que no ve, en modo alguno, don Quijote: tres damas hermosísimas sobre jacas ricamente enjaezadas. Hábilmente Sancho perfila iconos propios del universo en el que se siente don Quijote tan absorbido. Habiendo sido, hasta ahora, desconocedor y receloso del mundo caballeresco, Sancho se inicia ahora en la tarea de asumirlo, y hasta de imitarlo en su lenguaje, como lo ha aprendido de tanto escuchar a don Quijote a todo lo largo de la segunda salida. Por ello le habla a las tres aldeanas como lo hace, y como nunca lo hiciera de no estar delante don Quijote; es decir, de no ser consciente Sancho de que está interpretando, fingiendo, el papel de un real escudero de un no menos real caballero andante.

"Yo no veo, Sancho -dijo don Quijote- sino a tres labradoras sobre tres borricos" (II, 10, 706). Si no supiésemos que Sancho está mintiendo descaradamente, pensaríamos que se han trocado el cuerdo con el loco de momentos anteriores. Pero el caballero está pagando su manía de negar la realidad inmediata, que fue su primera y repetida conducta, y se lo está cobrando su escudero, en un claro gesto de egoísta deslealtad. Sancho no pierde ripio en sacar ventajas materiales de lo que acaba de inventar, pues si don Quijote le ofrece, como albricias -dándole a elegir- parte de lo que obtenga en una próxima aventura o tres crías de yegua de su hacienda, contantes y sonantes, el materialista vecino se inclina por la segunda oferta (¡qué poca fe tiene aún en las caballerías de su señor!), a la vez que Cervantes vuelve a jugar con ecos de aquella otras secuencia de Sierra Morena que estamos considerando como adelanto de la actual: allí Sancho le hizo escribir a don Quijote una manda por otros dos pollinos, al dorso de la misiva dirigida a Dulcinea.

Sancho tiene que esforzarse en que don Quijote admita su mentira. Y lo hace no solo mostrando la superchería, sino comportándose como actor de la misma. Asume parte del comportamiento quijotesco, que ante la perplejidad de su escudero, se comportaba acorde con la realidad que decía constatar ante su vista: por ello Sancho se adelanta y rinde pleitesía a la hermosa y distinguida dama tobosina ("Reina, y princesa y duquesa de la hermosura" (II, 10, 706)) cuando le presenta a su descolocado y perplejo amo. Su fingimiento está surtiendo efecto, pues don Quijote le imita. Sancho ha puesto a su señor ante una delicada contradicción: aceptar lo que le gustaría que fuera, lo que necesita que sea, pero que le niegan los datos sensibles de la conciencia, o rechazarlo de plano, poniendo en evidencia la orquestada mentira de la que se le quiere hacer víctima.

Como decía unas líneas más arriba, Sancho ha aprendido, como discípulo aventajado y estimulado por la necesidad, el lenguaje caballeresco de su amo (y, por ende, de los libros en que don Quijote se inspira) y hasta recuerda el sobrenombre de "Caballero de la Triste Figura", que Sancho dice siempre con indisimulado orgullo, porque a fin de cuenta él fue su acuñador en el capítulo XXI de la Primera Parte. Y su asimilación de la retórica caballeresca es también indicio, para don Quijote, de que su escudero ve lo que dice ver. Por ello, imponiéndose a sus primeras dudas, el caballero se apresura a dirigirse a la aldeana en similares términos, que son los ajustados en la caballería, si no es porque la mujer en cuestión se le adelanta con un registro coloquial, rústico que, sumado a la apariencia física que está viendo don Quijote ("moza aldeana y de no muy buen rostro", 
"carirredonda, chata"; II, 10, 706) traza completo retrato de la tal; y aun, con todo, lo hará cuando responda a la primera queja de la sayaguesa con una retahíla de vocativos ponderativos dignos de la dama más envidiablemente hermosa de la imaginería caballeresca: "estremo del valor que puede desearse", "término de la humana gentileza" (II, 10, 707). Porque en este retablo farsesco que el director de escena Sancho Panza ha ideado, aún no hemos parado mientes en la actuación de las tres mujeres, cuya marcha a las tareas agrícolas cotidianas se ha visto interceptada por "dos hombres tan diferentes" (en el sentido doble de 'distintos entre sí' y sobre todo 'diferenciados de los demás comunes', o sea, extemporáneos, atrabiliarios, casi carnavalescos). El carácter del personaje que ha elegido Sancho al azar, para fundamentar su invención, está a punto de echarlo todo a rodar. No hay posibilidad, por tanto, de una connivencia colaboradora como la había habido en el caso de Dorotea ni de seguir el juego, aunque fuese con exclusiva finalidad grotesca, al igual que en las gentes de la venta de la Primera Parte. No: por el contrario, la rústica sayaguesa hace honor a su rol literario y se toma la situación con enfado, rudeza y hasta grosería. Sancho, que ve peligrar su invento, vuelve a la carga procurando antes regalar los oídos recelosos del amo que convencer a la que parece inconvencible (por ello vuelve a referirse a aquél con la ponderación de "columna y sustento de la andante caballería"; II, 10, 707). Pero Sancho no ha medido bien sus posibilidades. Dorotea había accedido a ser Micomicona porque, en primer lugar, se le había explicado la situación, y además era personaje de mayor cultura y relieve social, y por tanto proclive para adaptarse a una ficción caballeresca, siendo ella misma personaje de otra ficción de aventuras. En cambio la aldeana que Sancho se ha topado en el camino no tiene capacidad alguna de doblez, no entiende más realidad posible que la que alcanza a su borrica, sus campos, sus tareas. Y todo lo que se sobresalga de tan concretos límites ha de ser entendido con el natural recelo del "engaño", de la "burla" del señorito contra el rústico (la tensión resuelta en comicidad de tanta farsa pastoril en la que el sayagués era personaje objeto de burla por su lengua rústica y por su ignorancia).

Es digna de encomio la fe de don Quijote en esta ocasión, como en tantas otras. Tiene delante a una mujer objetivamente fea ("contrahecha hermosura") ante la que muestra "sumisión y arrodillamiento" porque esa "fealdad" (es decir, esa falta de cualificación para ser dama de caballero andante) es un defecto aparente, debido al "maligno encantador" Frestón (o Merlín, según habrá de saber después) y -concediéndole a Sancho una credibilidad que no se ha merecido- por ello la cree suficientemente digna de amarla.

Cervantes llega al límite de lo grotesco: escuchamos por un lado la argumentación de don Quijote, implicando en él, y una vez más, el comodín del "encantador" como la impenitente sombra enemiga que le acompaña para desbaratar su caballería; y por otro, situándose en el extremo de la más completa incomunicación, las extemporáneas y enfadadas respuesta de la labriega, reduciendo las sentidas y elaboradas razones de don Quijote a intuidos "resquebrajos".

Con el "apartóse Sancho y déjola ir" (II, 10, 708) del párrafo siguiente la cuestión parecería zanjada. El grotesco no había hecho más que iniciarse, rodilla en tierra los dos extravagantes nómadas. Pero Cervantes no da por agotada la escena. Sabe que aún tiene posibilidad de abundar en ese grotesco. Para ello recurre a un movimiento que frecuentemente hemos visto adjunto a la suerte quijotesca (se reproducirá en el capítulo siguiente, cuando los dos andarines manchegos se topen con la compañía de cómicos de 
Angulo el Malo): el derribo de la montura al trote. Tantas veces le ha ocurrido al caballero, y ahora le ha de suceder a su dama, o a aquella aparente sayaguesa en la que está enmascarada, temporalmente, su dama. La mujer, entre airada y asustada, fuerza el trote de la borrica que, desacostumbrada a tales exigencias, la tira a tierra. La reacción de don Quijote no se hace esperar; es como si el encantador que lo persigue le concediese una satisfacción en medio de la frustración: la de izar amorosamente a la dama ofendida del suelo y llevarla en sus brazos a lugar tranquilo. Pero la realidad es engañosa muchas veces, los encantadores tienen a punto los resortes de la sorpresa que nos deja en vacío la víspera de cualquier gozo y cuado el caballero acude solícito, la dama ya está en pie, ha retrocedido unos pasos, ha iniciado una breve carrerilla, ha abordado la díscola caballería por atrás y de un salto se ha colocado de horcajadas sobre la pollina y ha reiniciado, con mayor seguridad, el nuevo trote. Sancho, que ha presenciado la habilidosa hazaña de "su Dulcinea" se hace lenguas de lo que ha visto y comenta, en elogio de la anónima muchacha, su capacidad de salto ("más que un acotán") y la destreza en montar la borrica ("puede enseñar a subir a la jineta al más diestro cordobés o mejicano", II, 10, 708), cualidad ponderada que no está muy lejos de aquella otra, sobre la potente capacidad de su voz, que, en su momento, había dicho de Aldonza Lorenzo: "Sé decir que se puso un día encima del campanario del aldea a llamar unos zagales suyos que andaban en un barbecho de su padre, y, aunque estaban de allí más de media legua, así la oyeron como si estuvieran al pie de la torre" (I, 25, 283). En la bruta realidad se abre paso la esquirla de la fantasía aventurera: "sin espuelas hace correr la hacanea como una cebra", dice Sancho, y tal habilidad en la cabalgada la ve pareja en las dos compañeras, o damas, de modo que "todas corren como el viento" (II, 10, 708). El resultado es otra vez la frustración moral de don Quijote: reaparece el mecanismo por el que se le hurta la vivencia caballeresca en el filo mismo de su aprehensión. Otra vez "la malicia y la ojeriza" del encantador de turno le priva a don Quijote, si no de la suprema ventura, de algo más importante todavía: de haber visto a su señora "en su ser". Don Quijote había acariciado por unos minutos, a la espera del regreso del embajador Sancho, la materialización de una utopía, que ahora es carne de quimera huida en forma de vulgar aldeana, como tantas otras quimeras, que escapa a trote de borrica. Mal empieza la tercera salida: con la decepción contraviniendo las buenas intenciones. Sancho, para escapar del compromiso, ha ido mucho más lejos de una inocente engañifa para superar el reto: ha creado en el ánimo de su señor un vacío, una desazón que no acabará sino con su vida y trayectoria cual caballero. Pero, a la vez y a modo de fértil compensación, generará en don Quijote el leit-motiv que le impulse continuadamente en esta tercera salida, cual será procurar el desencanto de su amada: ninguna empresa realizada y por realizar deberá ocuparle más tiempo y ganas que ésta, la suprema entre todas. Y así, cuantas sobrevengan no serán sino peldaños encaminados a la más importante. Don Quijote no descansará hasta ver desencantada, y vuelta a su ser, a la señora del Toboso. ¡Buena la ha armado Sancho! ¡Y bien que se ha de acordar de su estratagema, que lo seguirá poniendo a prueba!

Todavía antes de seguir adelante, que es seguir el rastro de este encantamiento inicial e iniciático, Cervantes nos deja otro valioso testimonio de cómo su particular "loco" va evolucionando en su modo de percibir y reelaborar la realidad. Ahora, como se decía, el proceso va tornándose inverso: cuando en la venta de la primera parte don Quijote abrazaba, en la oscuridad del desvencijado camaranchón, a la maloliente Maritornes (según información del narrador) olía en ella no el desagradable aliento "a ensalada fiambre y 
trasnochada" sino "olor suave y aromático" (I, 16, 173); ahora, en cambio, el mismo caballero reconoce que, al acercarse a la aldeana "me dio un olor de ajos crudos que me encalabrinó y atosigó el alma" (II, 10, 709). En la ocasión anterior la pituitaria quijotesca había anulado la sensación real para sustituirla por la teórica-caballeresca, según la cual toda dama que se precie de tal ha de oler a ámbar y flores, porque "el buen olor" les es consustancial. Ahora su cerebro ha recibido y procesado la desagradable impresión sensorial, y es la teoría-caballeresca la que, sin anularlo, lo justifica, lo "explica" como un signo más del encantamiento.

Por el portillo abierto por el mismo don Quijote -el subterfugio acomodaticio de los encantadores, que él no ha visto, pero que deben de andar por todas partes- se cuela Sancho a tiempo: rociada de maldiciones y lamentos a los tales, para intentar todavía una nueva manipulación de la realidad, por la palabra, en su favor. Y tenemos nueva ocasión para enlazar, por contraste, con el ya varias veces aludido episodio-embajada de Sierra Morena. Entonces era don Quijote el que corregía la descripción naturalista de la Dulcinea que Sancho decía haber visto en los términos que mejor se correspondían con el paradigma libresco de la caballería; ahora esa corrección, frente a lo que ha visto por sus propios ojos el caballero, la hace el escudero tomando pie en lo que ha ido aprendiendo de su señor, y sin poder evitar una indeliberada interferencia con la parodia en el modo de presentar lo que, desde la estética de Sancho, es signo de belleza y elegir una batería de elementos de comparación muy marcados por connotaciones de feísmo. El parlamento no tiene vocablo que no aporte algo a la comicidad buscada y que al mismo tiempo no dé cuenta de la sagacidad sanchesca en aprovechar a su favor las interpretaciones que admite Don Quijote: "Bastaros debiera, bellacos, haber mudado las perlas de los ojos de mi señora en agallas alcornoqueñas ["cecidias" o "bultos redondos que se forman en las cortezas de algunos árboles'], y sus cabellos de oro purísimo en cerdas de cola de buey bermejo, y, finalmente, todas sus facciones de buenas en malas, sin que le tocárades el olor" (II, 10, 709). Por el camino de la ironía disfrazada de protesta Sancho nos ha ampliado hasta el detalle el retrato de la sayaguesa que había hecho el narrador párrafos arriba, y resumido en "fea corteza". Y aún se matiza más en la última apostilla del socarrón mentiroso: "pero a decir verdad, nunca yo vi su fealdad, sino su hermosura [Sancho se declara al pairo de los efectos transformadores de los encantadores, para defender la buena fe de su embajada] a la cual subía de punto y quilates un lunar que tenía sobre el labio derecho a manera de bigote, con siete o ocho cabellos rubios como hebras de oro y largos de más de un palmo" (II, 10, 709). Sancho ha mezclado lo visto con lo imaginado (de oídas) y ha logrado un efecto chirriante: el "lunar sobre el labio" embellecía el rostro femenino y, por el contrario, la concentración de vello en el mismo lugar (la mujer bigotuda) la devaluaba hasta considerársela "cruel y peligrosa". Una síntesis contrastiva (belleza/fealdad al mismo tiempo) que Don Quijote advierte y no pasa por alto ("muy luengos para lunares son pelos de la grandeza que has significado" II, 10, 710).

En este episodio don Quijote experimenta en propia carne, y precisamente con la dama de sus pensamientos, algo que afirma en la secuencia siguiente (el encuentro con el fingimiento teatral) y que es básico en la concepción de todo el Quijote: "es menester tocar las apariencias con la mano para dar lugar al desengaño" (II, 11, 714). Ese largo camino hacia el desengaño que es, de algún modo, el segundo Quijote se inicia en esta experiencia. Y el impacto que le ha producido, lo acompañará de largo. 
Por ejemplo, en la importantísima experiencia caballeresca soñada en la espelunca de Montesinos (II, 23) don Quijote añade a los elementos del sueño que le presta la tradición romanceril carolingia (todo lo relacionado con el binomio Durandarte-Belerma) los propios, aportados por su subconsciente: y don Quijote vuelve sobre lo que le ha provocado intensa preocupación. Por ello ve desfilar, al mismo nivel que la contristada Belerma y sus damas o las nuevas metamorfosis del escudero Guadiana y de la dama Ruidera y sus siete hijaslagunas, a "tres labradoras que por aquellos amenísimos campos iban saltando y brincando como cabras; y apenas las hube visto, cuando conocí ser la una la sin par Dulcinea del Toboso, y las otras dos aquellas mismas labradoras que venían con ella, que hablamos a la salida del Toboso" (II, 23, 825-826). Ya tenemos elevada a verdad mítica la superchería de Sancho. Por primera vez se notan las huellas activas de su incidencia en la novela. Ese rincón onírico de Don Quijote se puebla como consecuencia de su ocurrencia. Don Quijote se encarga de revestirlo, de autorizarlo en el universo caballeresco. Implica la figura del mago Merlín (que bien podría ser una concreción del "encantador" que era responsable de la metamorfosis de Dulcinea) y añade circunstancias que interrelacionan la nueva experiencia soñada con la vivida: "Pregunté a Montesinos si las conocía, respondióme que no, pero que él imaginaba que debían de ser algunas señoras principales encantadas, que pocos días había que en aquellos prados habían parecido" (II, 23, 826). Si es Montesinos quien admite que se trata de "damas encantadas", la mentira de Sancho ya ha adquirido carta de naturaleza para Don Quijote; porque bien claro admite el caballero que si la reconoció en la visión de la cueva fue porque "trae los mesmos vestidos que traía cuando tú me le mostraste" (II, 23, 826). El cinismo de Sancho llega entonces a uno de sus máximos registros porque, sabiéndose causa principal de ese "sueño", se exculpa a sí mismo acudiendo a la desacreditación del loco. Por el contrario don Quijote se limita a amoldar la vigilia al sueño: y si la sayaguesa había salido corriendo ante la requisitoria de tan extraño hombre, también en la cueva "me volvió las espaldas, y se fue huyendo con tanta priesa, que no la alcanzara una jara ['un dardo']" (II, 23, 826-827). Y si en la primera ocasión la secuencia tuvo una derivación grotesca, no va a ser menos en la secuencia soñada, según la cuenta el caballero: que una de las aldeanas-damas de la encantada le solicite una ayuda económica para Dulcinea, ofreciéndole como prenda garante "un faldellín de cotonía", no deja de extrañar a don Quijote, porque es una anomalía contra la falta de contingencias y necesidades a socorrer con unos reales en el imaginario caballeresco. Y con la explicación que don Quijote se autoconcede, en boca de Montesinos, se vuelve a confirmar en la idea del encantamiento de la dama: "esta que llaman necesidad adondequiera se usa, y por todo se estiende, y a todos alcanza, y aun hasta los encantados no perdona" (II, 23, 827), lo que es un modo de conciliar el idealismo caballeresco con el realismo del mundo circundante, que progresivamente van confluyendo en el Quijote, según se avanza por su Segunda Parte. Pero no acaba en ese contrapunto la experiencia de la aldeana encantada tal como la revive don Quijote en el sueño subterráneo, sino que le da tiempo a cumplir con un explícito propósito que la prisa de la sayaguesa le impidió formular en su momento: la promesa solemne de que no cejará hasta desencantar a Dulcinea. La mentira para salir del paso de Sancho se convierte en el norte de don Quijote, que arrastrará también al escudero.

En efecto, el siguiente eco de esta invención lo encontraremos en uno de los episodios de la mansión de los Duques. Ahora el papel de generador de la ficción que había ejercido Sancho lo asumen los anfitriones. Al comienzo de II, 34 leemos: "confirmándose en la 
intención que tenían de hacerles algunas burlas que llevasen vislumbres y apariencias de aventuras, tomaron motivo de la que don Quijote ya les había contado de la cueva de Montesinos, para hacerle una que fuera famosa" (p. 912). El interés, sobre todo, de la Duquesa por el asunto del encantamiento de Dulcinea viene de días atrás, de cuando en una conversación privada -II, 33- Sancho ha satisfecho la distinción de verse atendido por tan digna señora y le ha contado con pelos y señales a la ilustre dama lo ocurrido con la aldeana sayaguesa cerca de El Toboso. Los Duques tienen toda la información necesaria, incluida probablemente la referencia que, dijo don Quijote, había hecho Montesinos al sabio Merlín como directo encantador de cuantas figuras habitaban las profundidades de la cueva manchega. No tenían más que recuperar y trenzar esos datos en una nueva escenificación, que revalidara el motivo del encantamiento y avanzase un paso más, paso que -así parecen quererlo- viniese a ser castigo de quien lo había generado para salvarse de no ser pillado en falta, si originando por ello la tristura de su noble amo ${ }^{7}$. Y sobre todo porque en esa conversación la Duquesa ha notado en Sancho una credulidad más admirable que la misma locura de don Quijote, locura que su servidor pondera como coartada propia. Basta que la aristócrata, desde el ascendiente y rango que ejerce sobre Sancho, afirme que la aldeana encontrada en el camino era (al margen de la voluntad de engañar de Sancho) la efectiva Dulcinea sometida a auténtico encantamiento, para que Sancho lo admita: es como sentirse descargado de una responsabilidad, y desde luego ajeno a lo que ello conlleva para su señor y la dama de su corazón: "si mi señora Dulcinea del Toboso está encantada, su daño ['peor para ella'], que yo no me tengo de tomar, yo, con los enemigos de mi amo, que deben de ser muchos y malos[...] y si aquella era Dulcinea, no ha de estar a mi cuenta ni ha de correr por mí ['no me han de acusar de ello, yo no tengo la culpa de tal cosa']" (II, 33, 910). A la Duquesa le molesta ese egoísmo inhibitorio del servidor... y se lo hará pagar caro: quien se quiere apartar de toda implicación del encantamiento de la dama, que tanto importa a su señor, se verá metido de hoz y coz en el problema, iy de qué modo! Es ahora cuando Sancho va a ser puesto de nuevo a prueba.

Todos recordamos la escena, digna del mejor registro de lo teatral en la novela. En el capítulo 35 de Quijote II se abre ante las perplejas miradas de Sancho y Quijote una procesión en varios carros, y en el principal aparece la figura de Merlín y a su lado un ser de aspecto ambiguo (tanto como que es un ejemplo de travestismo de los que tanto abusó la escena, solo que al contrario: en esta ocasión hombre disfrazado de mujer) que representa a Dulcinea (¡no hay modo - parece decirnos la ironía cervantina- de que don Quijote contemple en momento alguno a su Dulcinea en su ser!). La escena tiene una doble intención comunicativa en razón de las respectivas preocupaciones de los dos concretos espectadores a los que va dirigida la representación: don Quijote confirmará de boca del auténtico encantador Merlín la situación que "envuelve" a su dama, y Sancho se llevará la sorpresa de verse totalmente implicado en la resolución del problema. La puesta en escena resulta cuidada hasta en el menor detalle; todo se encamina a suscitar el suficiente impacto y posterior sorpresa en los dos hombres. Primero en el discurso versificado de Merlín; después en el parlamento de la falsa Dulcinea. Sancho, de entrada, se ha declarado

\footnotetext{
${ }^{7}$ Pese a que el escudero ha intentado zafarse ante la Duquesa de dicha responsabilidad: "yo fingí aquello por escaparme de las riñas de mi señor don Quijote, y no con intención de ofenderle; y si ha salido al revés, Dios está en el cielo, que juzga los corazones" (II, 33, 909).
} 
irresponsable del hecho y por tanto ajeno a la cooperación que se le pide: pegarse tres mil y trescientos azotes. Las razones de Dulcinea le cierran más la posible salida, intensifican su puesta a prueba, haciéndole ver que el esfuerzo y el sacrificio que se le pide no es proporcional a lo "melindroso y esquivo" que se muestra. Aquella decisión de convertir a Dulcinea en una rústica aldeana, que al fin tenía su primera causa en la filiación declarada por don Quijote, ha acabado poniendo a Sancho en la más comprometida de sus situaciones. Su prudencia y su socarronería le recomendarán aceptar de entrada, ganar tiempo, simular... pero Sancho tiene enfrente un compromiso imposible de olvidar, de anular, de disimular, porque en él fundamenta su última razón de ser Don Quijote. Cuando Sancho, tras pactar, acepta, el carro de Merlín desaparece, y con él -definitivamente para siempre- la ambigua efigie de Dulcinea que, una vez desvelada, su rostro "a todos pareció más que demasiadamente hermoso, y con un desenfado varonil y con una voz no muy adamada" (II, 35, 924).

Acabaré: cuando Don Quijote entra por última vez, y por su pie, voluntariamente, en su aldea para cumplir el compromiso pactado y perdido en las playas de Barcelona, regresará por última vez la sombra-luz de Dulcinea, la aldeana encontrada en el bosquecillo manchego. Sancho se ha mantenido resbaladizo e inconstante en el cumplimiento del compromiso contraído y prometido ante Merlín. Don Quijote intuye que se acerca el final, y que su Dulcinea sigue lejos, en la cárcel del encantamiento, sin que haya logrado la definitiva y generosa aportación de su escudero. Cuando ambos llegaban a El Toboso (volvamos al comienzo) notó el caballero que se podía torcer el propósito de ver a su dama (como así fue) por unos agüeros negativos (diversos ladridos, maullidos, rebuznos, gruñidos de puercos y soledad total en las calles). Ahora, a las puertas del lugar de la Mancha en donde se inicia la novela, encuentran a dos muchachos riñendo, y don Quijote se queda impresionado al captar una frase de la discusión ("no la has de ver en todos los días de tu vida") y, como si fuera voz de agüero, la aplica a su desventura: no volverá a recuperar jamás a Dulcinea. Sin decirlo, hay dolido reproche a Sancho en la queja, y el escudero se saca una carta de la realidad vulgar que él bien maneja y opone al primer indicio de su señor otro igualmente ambiguo e igualmente cierto. Dejo la palabra a Cervantes:

Queríale responder Sancho, cuando se lo estorbó ver que por aquella campaña venía huyendo una liebre, seguida de muchos galgos y cazadores, la cual, temerosa, se vino a recoger y a agazapar debajo de los pies del rucio. Cogióla Sancho a mano salva y presentósela a don Quijote, el cual estaba diciendo:

- ¡Malum signum! ¡Malum signum! Liebre huye, galgos la siguen: ¡Dulcinea no parece!

-Estraño es vuesa merced -dijo Sancho-. Presupongamos que esta liebre es Dulcinea del Toboso y estos galgos que la persiguen son los malandrines encantadores que la transformaron en labradora: ella huye, yo la cojo y la pongo en poder de vuesa merced, que la tiene en sus brazos y la regala: ¿qué mala seña es ésta, ni qué mal agüero se puede tomar de aquí? (II, 73, 1210-1211)

El breve incidente, con sus dos partes claramente diferenciadas, es toda una situación emblemática del dolorido sentir quijotesco, ahora que se encamina al definitivo final, y del pragmatismo, cada vez más sagaz y oportuno, que va desarrollando Sancho. Si le damos credibilidad a una frase sacada de su contexto (como pretende hacer don Quijote) y proyectamos en otra cosa mucho más trascendida lo que no es más que una ocasional pelea 
por una simple jaula de grillos, corremos el riesgo de entender equívocamente la realidad, y mucho más la mirada prospectiva de esa realidad. En cambio, Sancho opera con el recurso pedagógico del ejemplo operativo y manifiesto ante el discípulo, para que induzca la abstracción: una liebre indefensa que huye de quienes se proponen agredirla; él la libera de ese riesgo y la entrega, sana y salva, a don Quijote. ¿Quién se atreve a afirmar que al final, aunque sea un poco fuera del tiempo, Sancho no ha cumplido con lo prometido ante Merlín y los Duques? Ni una palabra, ni un reproche más (salvo la sorprendente observación de Sancho acerca de lo poco oportuno que debe resultarle al cristiano viejo creer en supercherías: un racionalismo que es de cuño cervantino).

Todavía el taciturno don Quijote, al filo de retornar a su ser primero, acaricia por un instante la idea del reencuentro con Dulcinea, pero en forma de pastora... No pasa de un vago propósito dicho en el centro del enemigo (entre los pastores invitados a acompañarle estaría el malévolo y fingidor Carrasco). La muerte llega y solo queda el vago recuerdo de una antipática aldeana que un día pasó como una exhalación por el lado de don Quijote y apenas le dejó ni el excelente olor que debía de compartir con las Orianas que en el mundo han sido. Si don Alonso dio vida a don Quijote, a Sancho le cupo el honor de convertir en una quimera a la anónima villana de Sayago. De su inteligente glosa concluía don Miguel de Unamuno, desde otra perspectiva que: "a mí me apesadumbra tanto que me priva de imaginación para rehacerla" y, por tanto, "no puede leerse sin angustia este martirio del pobre Alonso".

\section{REFERENCIAS BIBLIOGRÁFICAS}

Deliberadamente he descargado el presente comentario de todo apoyo bibliográfico porque he preferido hacer una lectura directa del motivo elegido, sin trufarlo de continuas referencias a otros trabajos que se han aproximado, de forma más o menos específica, a este interesante episodio quijotesco y su proyección en el resto de la obra. No obstante, y para consulta del lector interesado, enumero ahora diversos trabajos que considero importantes en relación con el mismo.

ALLEN, John J., "El desarrollo de Dulcinea y la evolución de don Quijote", NRFH, XXXVIII (1990), pp. 849-856.

AUERBACH, Erich, Mimesis, México, FCE, 1950 (reimpresión 1983), pp. 314-339.

CLOSE, Anthony A., "Don Quijote's Love for Dulcinea: a stduy of cervantine irony", Bulletin of Hispanic Studies, L (1973), pp. 237-255.

HERRERO, Javier S., "Dulcinea and her critics", Cervantes II, 1982, pp. 24-42.

MÁRQUEZ, Héctor P., La representación de los personajes femeninos en el Quijote, Madrid, Porrúa Turanzas, 1990.

REDONDO, Agustín, "Del personaje de Aldonza Lorenzo al de Dulcinea del Toboso: algunos aspectos de la invención cervantina", Anales Cervantinos, XXI (1983), pp. 9-22.

WILLIAMSON, Edwin, "Intención and invención en el Quijote", Cervantes VIII (1988), pp. 7-22. 